\title{
Transport Costs in the Automotive Supply Chain
}

\author{
Domenico Gattuso, Gian Carla Cassone and Antonella Polimeni \\ DIIES (Engineering Department of Information, Infrastructures and Sustainable Energy), Mediterranea University of Reggio \\ Calabria, Reggio Calabria 89100, Italy
}

\begin{abstract}
The study, carried out within the LogNet research project financed by Calabria region, deals with the analysis of the automotive supply chain. In particular, after a first examination of the characteristics of the whole automotive supply chain, attention was focussed on its final part, that is, on transport and end-market distribution. The paper proposes specific models, which are differentiated by the transport mode (road, rail, sea) they are involved, to estimate the temporal and monetary costs related to the activity of goods distribution to the compounds/end-clients. The proposed modelling formulations concern two different areas of investigation: the network segment and interchange nodes. Each cost item is also calculated through aggregate formulations (where the cost is function of a single significant variable in relation to a unit cost parameter) and disaggregate formulations (where each cost item is separately considered). The models have been applied to a study carried out for the modal transfer of vehicles in the port of Gioia Tauro, south of Italy. The analysis has allowed, on the one hand, to calibrate certain models and, on the other, to simulate certain scenario hypotheses to verify the technical feasibility of a different structure for the automotive supply chain in Italy.
\end{abstract}

Key words: Automotive supply chain, transport costs, method and models.

\section{Introduction}

If logistics has assumed a strategic role for the competitiveness of enterprises [1-4], there is a field where it is particularly important: the automotive industry. This sector includes most of the critical aspects of logistics: long distances, customerization of products and necessity of assuring a high level of reliability in all the links of the chain in order to avoid the damaging of the transported vehicles. These elements can complicate the organization of the internal and external logistics of production and distribution of an automotive supply chain.

As a result, a study has been developed to define a methodological procedure for a better representation of the supply of the logistic and transport services, which underlie the distribution processes of the automotive supply chain, both in topological terms (graphs) and in performance terms (cost functions), from the point of view of a MTO (multimodal transport operator).

Corresponding author: Gian Carla Cassone, Ph.D., research fields: transport and logistics. E-mail: giancarla.cassone@unirc.it.
Attention has been mainly focussed on the phase of distribution and transport to the end-markets, knowing that, in most cases, the transport of vehicles is performed in a combined way, that is to say, it implies different modes of transportation (sea/rail, sea/road and rail/road).

The research refers to a scientific research project named LogNET: an innovative network for the development of logistics in the area of Gioa Tauro. The project, promoted in 2005 by Calabria region, the Ministry of Economy and the Ministry of Scientific Research, aims at promoting integrated initiatives of basic and industrial research for the promotion of a technological district of logistics and transformation in the area of Gioia Tauro.

The proposed procedure has also been applied to the transport logistic chain that is now operating in Gioia Tauro and is managed by BLG-Automobile Logistics Italia.

\section{Automotive Supply Chain}

An automotive supply chain includes the whole of the activities connected with the production and 
distribution of a motor car from its origin to its destination.

While it is not difficult to find references in literature concerning the automotive supply chain (supply and assembly of raw materials for the composition of the end-product $[5,6])$, studies and researches about the evaluation of the performances and of the costs of the product distribution phase are not numerous. In this study, it has been tried to adapt the models applied to the transport/distribution phase of a supply chain, which is found in literature, to the specific case of the transport of new motor cars that, due to their peculiarities, are characterized by needs and requirements different from any other type of industrial goods.

To put it briefly, the automotive supply chain can be divided into three components (Fig. 1):

- supply of raw materials (steel and metal components, rubber, electronic components, plastics, glass, textiles, etc.);

- assembly of raw materials for the realization of the end-product;

- distribution.

The above-mentioned phases imply the involvement of different actors, whose number can change according to the size of the supply chain (Fig. 2).

An alternative schematization of the automotive supply chain is shown in Fig. 3. It is possible to distinguish added cost activities and added value activities: the former include those logistic services which do not increase the value of the product but only the cost of the whole supply chain, such as the storage phases (the segments representing these phases have no slope); the latter include all those phases where each cost increase corresponds to a rise in the quality and value of the product (production, processing and transportation).

This paper specifically focuses on the final phase of the automotive supply chain, that is, on the transport and distribution phases, from the point of view of an MTO operating on behalf of a company.

\section{Methods and Models for Evaluating Logistic Costs}

The evaluation of the temporal and monetary logistic costs of a motor car should include both the costs incurred by the company of logistic services and those incurred by end-clients, assuming that the supply chain can be divided into four phases: supply of raw materials, processing, production and distribution.

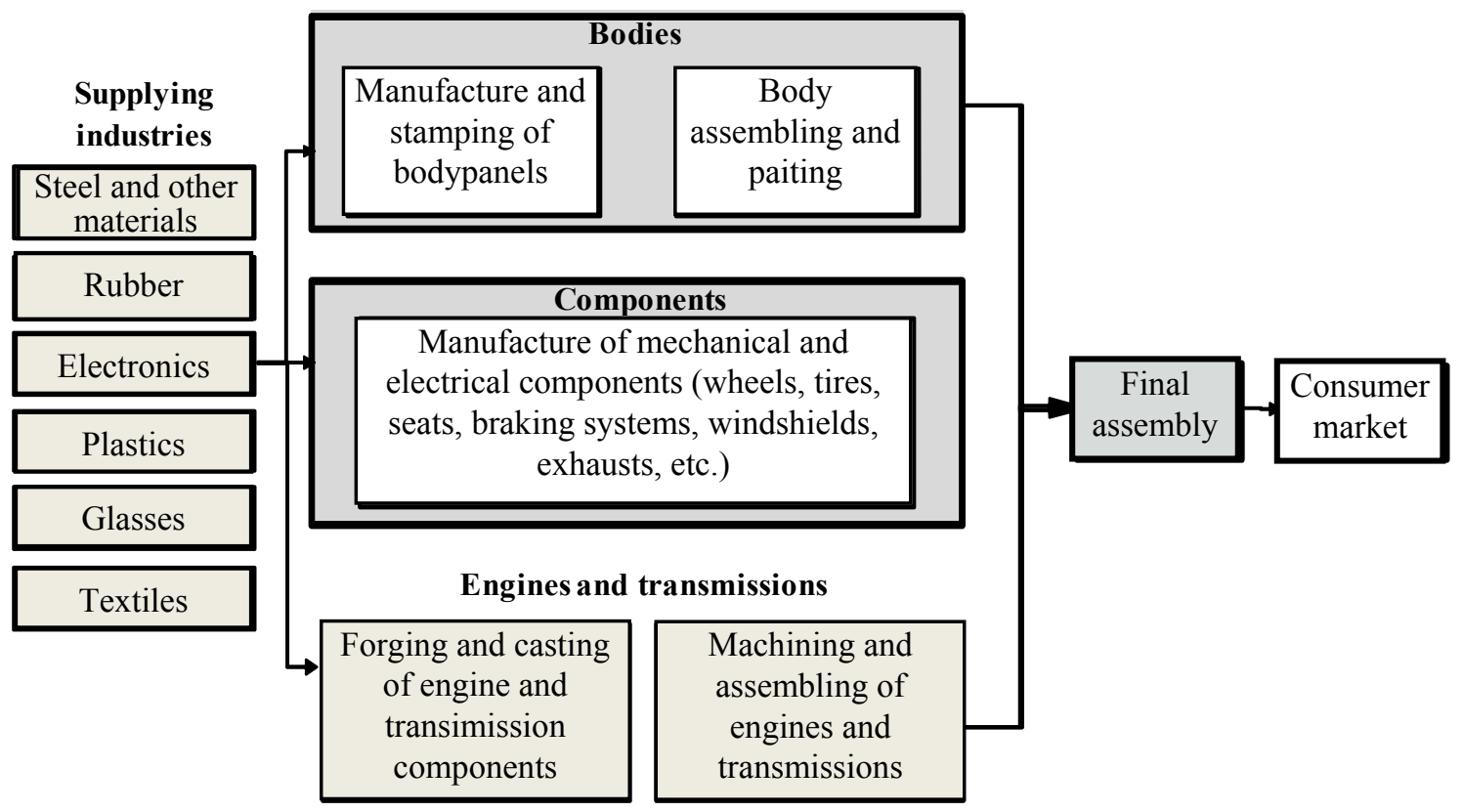

Fig. 1 Example of automotive supply chain [5]. 


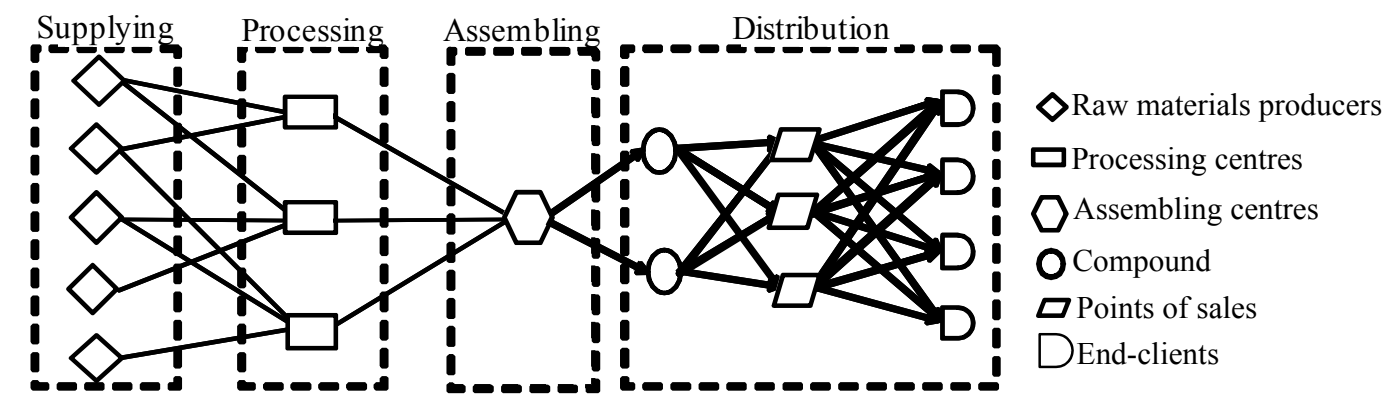

Fig. 2 Phases of an automotive supply chain.

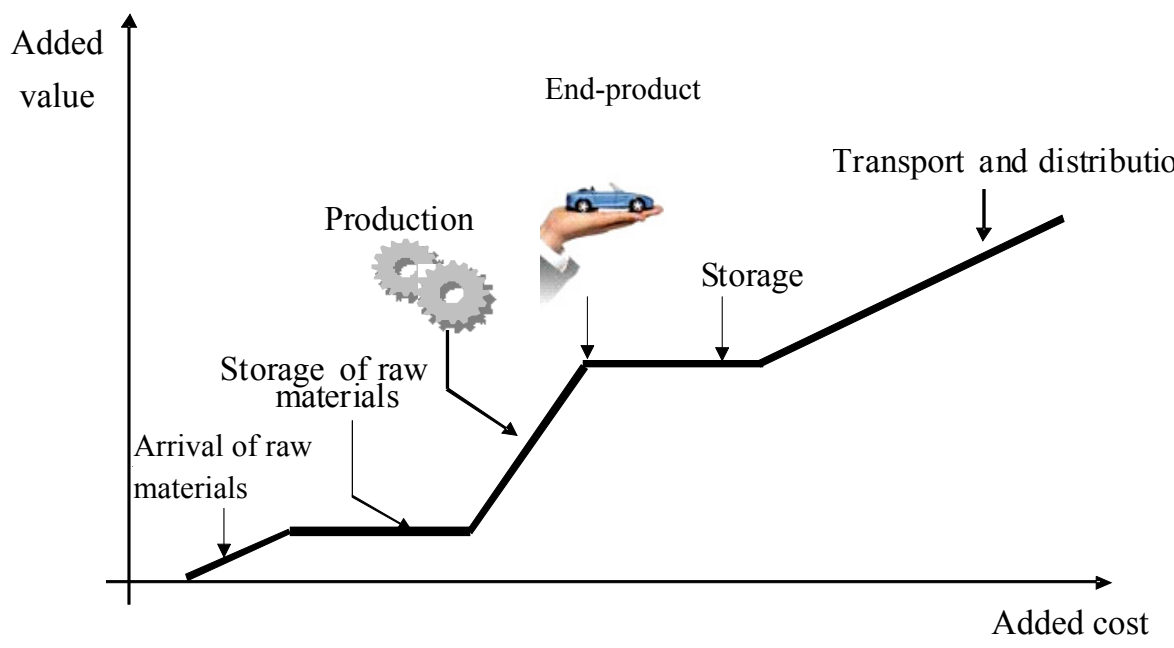

Fig. 3 Added costs and values in the automotive supply chain.

Further in this paper, certain literature models are presented and alternative models are proposed for the determination of the temporal and monetary costs of the transport and distribution phases of the automotive supply chain. A distinction is made between the costs related to the transport network and those occurring at transport nodes. Particularly, both aggregate and disaggregate cost models are proposed. The use of generalized cost functions has been excluded since the homogenization of times and monetary costs would conceal the single cost rates of the whole transport phase. Furthermore, if generalized costs functions were chosen, it would be necessary to define, together with the multimodal transport operators or with customers, the monetary value to associate to the time attribute, as well as to give a value to the reliability parameter of transport, which cannot be ignored in the sector of new motor cars.

The cost evaluation is referred to a standard consignment (cluster of cars), first effectuated by using a ro-ro (roll on-roll off) ship and then distributed via rail, road or sea. Because of the different capacity of the above-mentioned transport units (car transporters, car-transporting wagons and ro-ro ships), the cost evaluation inevitably takes into account also the availability of a sufficient number of means of transport to transfer the $n_{a}$ motor cars which form the standard consignment (e.g., 2,000 units).

The monetary and temporal cost functions can be represented as linear distance functions (Fig. 4) because the crucial element, on which the roles and functions of the intermodal transport strictly depend, derives from the division of the whole distance into partial routes, each to be covered by a specific carrier, in order to minimize the costs connected with the goods transferred from the origin to the destination.

These diagrams allow to evaluate a break-even distance between the considered transport modes. In particular, such a distance is the limit above which it is more convenient to choose a transport mode rather than 

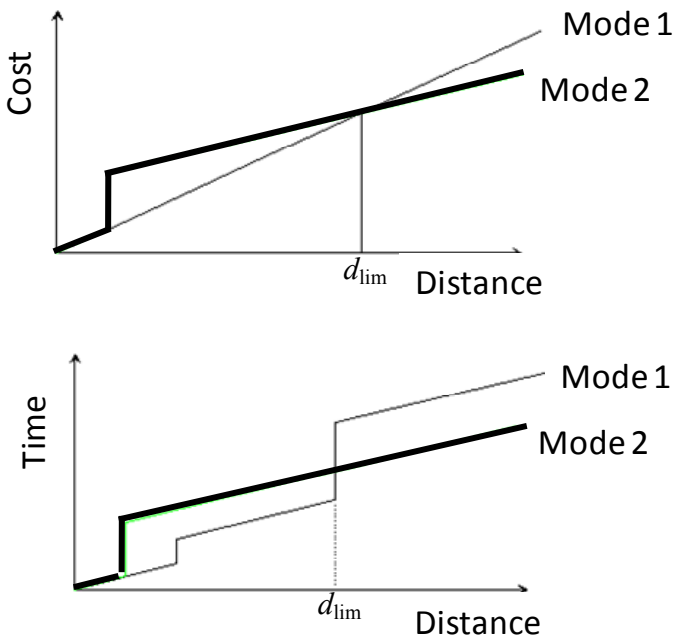

Fig. 4 Cost/distance diagrams.

another, it can vary according to whether the time or the monetary costs, necessary for the production of the transport service, are taken into account.

This type of analysis, known as break-even analysis, allows to get valid information to choose the most favourable transport mode, or combination of transport modes, in terms of time and money, for a consignment.

Ultimately, the result of this research is the formulation of a specific and systematic framework concerning the models for the calculation of times and costs associated only to the distribution phase of a supply chain. This has been obtained by adapting the values of the parameters and coefficients present in the literature models to the specific case of car transportation, as well as thanks to the precious collaboration of certain big enterprises of the sector.

Another new element is the specification of the port node. There are certain models in literature which analyzes the port terminal in terms of network, that is, by splitting what happens in the port area into elementary sub-activities, each of them associated to functions for the evaluation of monetary and temporal costs. The disaggregate model, proposed for the representation of the port node, is an original model, specifically adapted to the transportation of new motor cars and it is still in progress, that is why the results presented in the final application have been obtained through the application of the proposed formulations in the aggregate approach.

\subsection{Costs on the Network}

The main rate of the cost on network is associated to the transport phase, therefore, this cost changes sensibly according to the used transport mode: road, rail or sea. Specific models for the calculation of the temporal and monetary costs of the three transport modes are proposed further on.

The road monetary cost for a single car transporter (and, as a consequence, for a number of motor cars which can vary depending on their sizes) can be evaluated through the following aggregate model:

$$
c_{s}=\alpha_{s} \cdot L
$$

where, $L$ is the distance covered by road and $\alpha_{s}$ is the kilometric cost, expressed in $€ / \mathrm{km}$.

Certain studies (SCENES-Scenarios for European Transport [7], Trimac Logistics [8] and Tuttotrasporti [9]) report an average transport unit cost on the Italian territory equal to $1.32 € / \mathrm{km}$ : this value is an average result referring to generic goods. In the case of car transportation, the value of the parameter $\alpha_{s}$ is higher: this parameter has been fixed by the National Collective Agreement for the transportation of vehicles (Bonforti Act) as shown in Fig. 5. In particular, the parameter assumes a higher value when the possible damages to the transported goods are charged to the person who operates the transport (Contract "A"), it assumes a lower value in the opposite case (Contract "B").

The total road cost for the standard consignment can be calculated by multiplying the cost associated to the single car transporter by the number of car transporters $n_{b}$ used for the transportation.

$$
C_{s}=c_{s} \cdot n_{b}=c_{s} \cdot\left[\operatorname{int}\left(\frac{n_{a}}{W_{b}}\right)\right]
$$

where, $n_{a}$ is the overall number of motor cars (referred to the standard consignment) and $W_{b}$ is the car transporter capacity. 


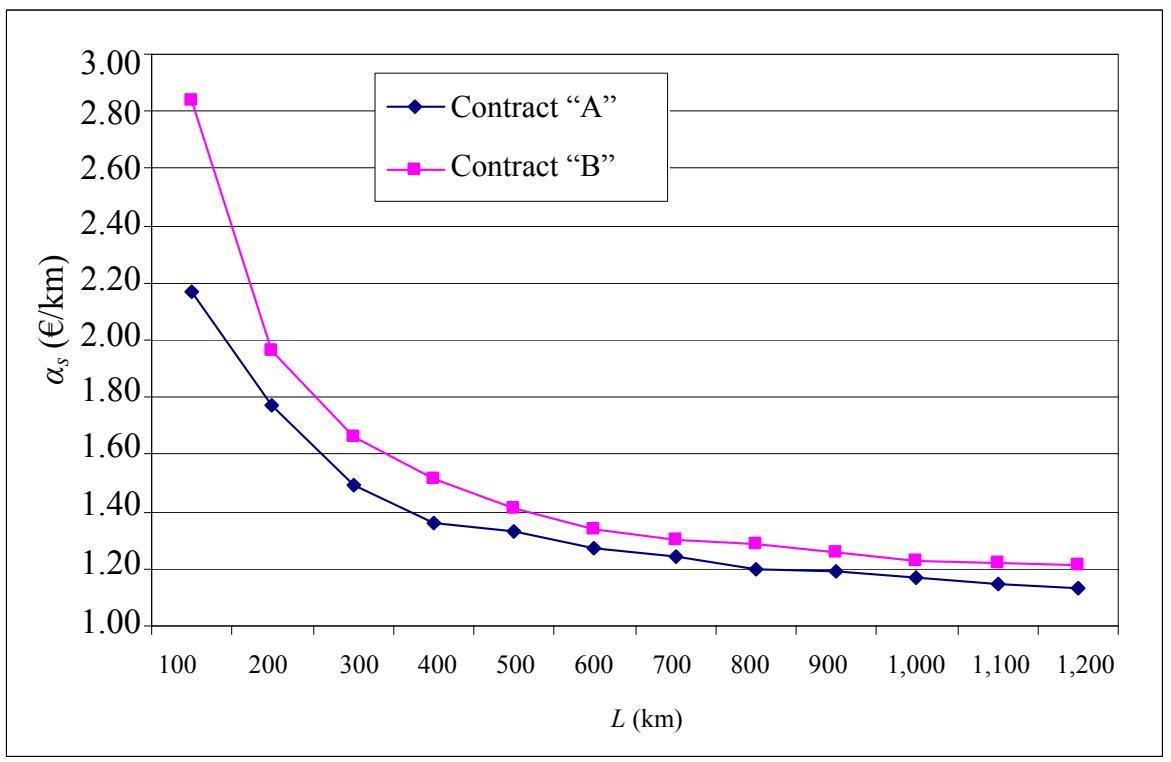

Fig. 5 Kilometric cost trend of road transportation.

The $T_{s}$ (road temporal cost) can be evaluated as the sum of an additive rate $T^{4}$ (equal to the overall travel time $T_{v}$ ) and a non additive rate $T^{N A}$ which includes the stop time $T_{f}$ and the dwell time $T_{w}$, imposed by the current regulation:

$$
T_{s}=T^{A}+T^{N A}=T_{v}+T_{f}+T_{w}
$$

In other terms:

$$
T_{s}=\frac{L_{s}}{v_{s}}+T_{f o} \operatorname{int}\left(\frac{T_{v}}{T_{v s}}\right)+T_{w o} \operatorname{int}\left(\frac{T_{v}+T_{f}}{T_{w s}}\right)
$$

where, $L_{s}$ is the long distance, $v_{s}$ is the average speed, $T_{f o}$ is the shorter stop time, $T_{v s}$ is the maximum trip time beyond which a shorter stop is obligatory, $T_{w o}$ is the obligatory longer stop time, $T_{w s}$ is the maximum trip time beyond which a longer stop time is obligatory.

The parameters introduced in the above-mentioned formula are relevant to the industrial nature of the transported goods, in particular, as far as Italian rules are concerned (Highway Code, 2004):

$$
T_{s}=\frac{L}{v}+0.5 \operatorname{int}\left(\frac{T_{v}}{4.5}\right)+7.5 \operatorname{int}\left(\frac{T_{v}+T_{f}}{10}\right)
$$

where, times are expressed in $\mathrm{h}$.

Even in the railway case, it is possible to distinguish between monetary and temporal costs.

In the reasonable case when the railway car transportation is carried out by means of a complete block train, the monetary cost $c_{f}$ of the single train can be calculated as a function of the unit cost per wagon $\alpha_{c}$ and of the number of railway wagons $n_{c}$ :

$$
c_{f}=\alpha_{c} \cdot n_{c}
$$

The unit cost coefficient $\alpha_{c}$ depends on the distance between the origin and the destination of the consignment. In field literature, certain studies, which take into account coefficients calibrated for different $\mathrm{O} / \mathrm{D}$ (origin/destination) couples, have estimated an average value per wagon of $2.7 € / \mathrm{km}$.

Like in the case of road transport, the total cost to move $n_{a}$ motor cars by railway transport can be obtained multiplying the monetary cost related to the single train by the number of necessary trains $n_{f}$.

$$
C_{f}=c_{f} \cdot n_{f}=c_{f} \cdot \operatorname{int}\left(\frac{n_{a}}{W_{f}}\right)
$$

where, $W_{f}$ is the capacity of the single train.

The temporal cost on the railway section can be calculated by considering the scheduled timetable of the railway companies. Starting from an Italian database, an average speed $v_{f}$ equal to $80 \mathrm{~km} / \mathrm{h}$ has been assumed. Therefore, the overall travel time on the network can be evaluated dividing the distance covered 
by rail by the average speed $v_{f}$ :

$$
t_{f}=\frac{L_{f}}{v_{f}}=\sum_{i} \frac{L_{f i}}{v_{f i}}
$$

where, $v_{f i}$ varies according to the characteristics of the line component $L_{f i}$.

The evaluation of the monetary and temporal costs along the sea section, whether ocean or feeder, can also be obtained through aggregate models.

In particular, as far as the total monetary costs are concerned, they can be calculated by multiplying the unit cost $\alpha_{m}$, relevant to the transportation of a single motor car by the number $n_{a}$ of embarked cars:

$$
C_{m}=\alpha_{m} \cdot n_{a}
$$

The unit cost varies depending on the quantity of transported motor cars (following a policy of economy of scale). The interdependence between the two values, calculated through direct observations, is shown in Table 1.

The values of the parameter $\alpha_{m}$ can considerably vary when the transportation of the $n_{a}$ motor cars needs a number $n_{n}$ of ships higher than one.

Also in the case of the sea temporal cost, the simplest expression is that where the trip time is expressed as a function of the distance to cover $L_{m}$ and of the speed of navigation $v_{m}$ :

$$
t_{m}=\frac{L_{m}}{v_{m}}
$$

Furthermore, in this case, there are different variables which could influence the trip time, for instance, bad weather and sea conditions could modify the departures/arrivals of the ships even of $24 \mathrm{~h}$ to $48 \mathrm{~h}$.

\subsection{Costs at the Nodes}

There exist two different typologies of nodes: business node and interchange node. In business node,

Table 1 Relation between number of motor cars and transport unit cost on maritime network.

\begin{tabular}{ll}
\hline Number of motor cars & $\alpha_{m}(€ /$ car $)$ \\
\hline$\leq 300$ & 281 \\
$301-600$ & 182 \\
$\geq 600$ & 165 \\
\hline
\end{tabular}

motor cars are processed, stored and prepared for the transportation up to the end-client. It is clear that monetary and temporal costs correspond to the operations carried out within the company (internal handling, storage and stocks). On the contrary, the interchange transport node represents a particular point of the transport network where the exchange between two means of transport takes place.

The cost at the interchange node often determines the competitiveness of the alternative routes/modes of transportation because it can make a supply chain cheaper than another, e.g., intermodal transport is cheaper than the monomodal one. This cost depends on the modes of transport involved in the interchange and on the functional organization of the activities in the node.

This is the reason why it is necessary to optimize the operations at the interchange node in order to reduce the cost and duration of the transfer operations.

Over the last few years, policies for the reduction of transport costs at interchange nodes have been brought about: computerized systems for the management of information (EDI (electronic data interchange) type); more efficient vehicles; better organization of the node.

The evaluation of the monetary and temporal costs, related to the transit of goods through the interchange node, can be carried out by the following two different approaches: disaggregate and aggregate. In the first case, the cost items, forming the total cost associated to the transit of the goods, are explicitly considered. In the second case, the monetary and temporal cost is represented by a single parameter.

\subsubsection{Disaggregate Approach}

The interchange nodes are involved in many activities which vary according to the typology of node and of traffic. These activities imply monetary and temporal costs which have to be incurred by an MTO that wants to make a consignment by using combined transportation (road/rail, road/sea and rail/sea). Consequently, in a transport network, the 
interchange nodes cannot be represented as a simple "stop" node. A higher disaggregation is necessary in order to accurately evaluate the time and cost components connected with the transport of goods (motor cars). With a view to represent in details what happens at the interchange node, a graph has been designed, whose links stand for the activities which take place at the interchange terminal, while nodes represent physical and/or temporal points of starting/ending of the same activities.

In the case of transportation of motor cars, the intermodal railway terminal allows the transfer of the vehicles from the car-transporting wagons to the car transporters or to the ro-ro ships and vice versa. In this case, except for the areas dedicated to the storage of the motor cars, it is not necessary to have sophisticated equipments for the handling of the vehicles, since they are handled directly by specialized workers. A particular attention has to be paid to the safety/quality of the handling phase, because any damage to a motor car becomes an element which will exponentially increase the transport cost.

The graph in Fig. 6 shows a railway terminal. When the railway is clear, the goods train is sent on the network (link 0-1) and enters the terminal (link 1-2) where unloading operations take place (link 2-3). The unloaded motor car is moved to the storage area (link 3-4) from where, after a certain stop (link 4-5), it is sent to the area for the setting up of the car transporters (link 5-6). Then, the trailer truck is formed (link 6-7) and, after the fulfilment of the possible customs duties (link 7-8), it can be put on the road network (link 8-9). Once the unloading operations are completed, the train is rearranged (link 4-15). Then, after the customs check (link 10-11), the car transporters coming from the road network (link 9-10) are unloaded (link 11-12) and motor cars are stored in the yard (link 12-13) from where they will be moved towards the area for the train preparation (link 13-14) and loaded on the train (link 14-15). Finally, the train is "delivered" to the nearest station (link 15-0) and, after several check operations, is sent to the railway network.

In the case of maritime transportation of motor cars, the port node is a ro-ro port.

The port node supply can be represented by means of a graph divided into two sub-graphs (Fig. 7):

- sea side sub-graph, which schematises the entrance/exit operations via sea, from the entrance of the ship in the roadstead up to its docking and vice versa;

- land side sub-graph, which schematises the operations of the ship load/unload, handling and storage activities in the yard, goods routing on land transport networks.

The phases characterizing the entrance of the ship into the port are pilotage (link 0-1), towing (link 1-2)

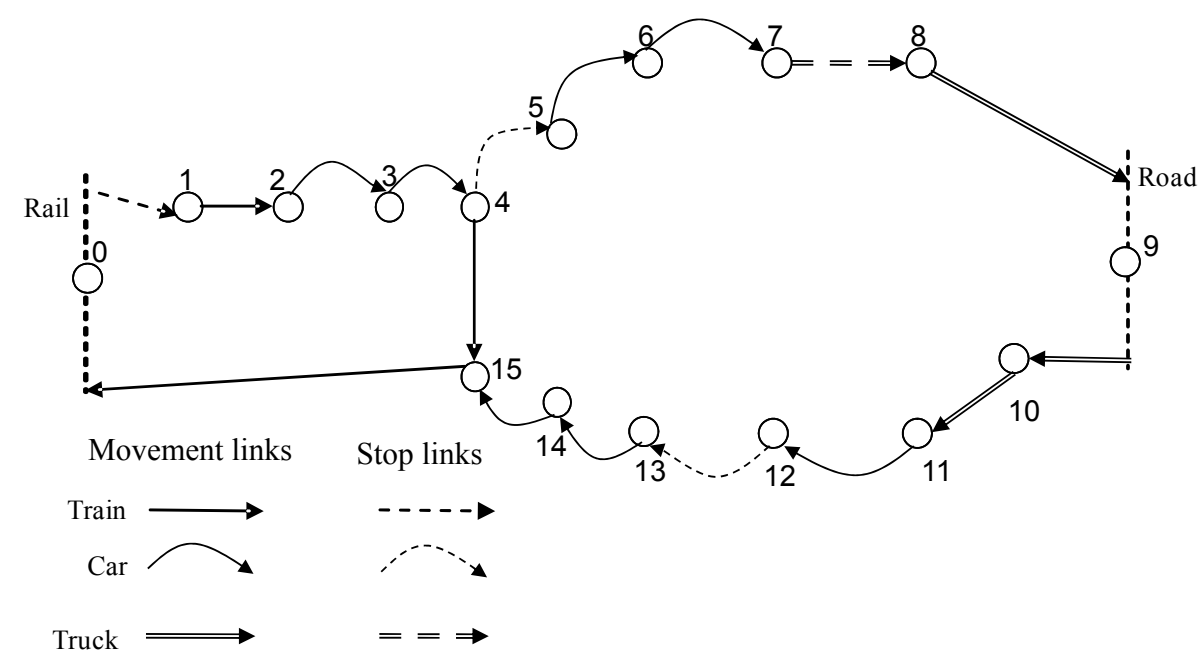

Fig. 6 Rail/road exchange node graph. 


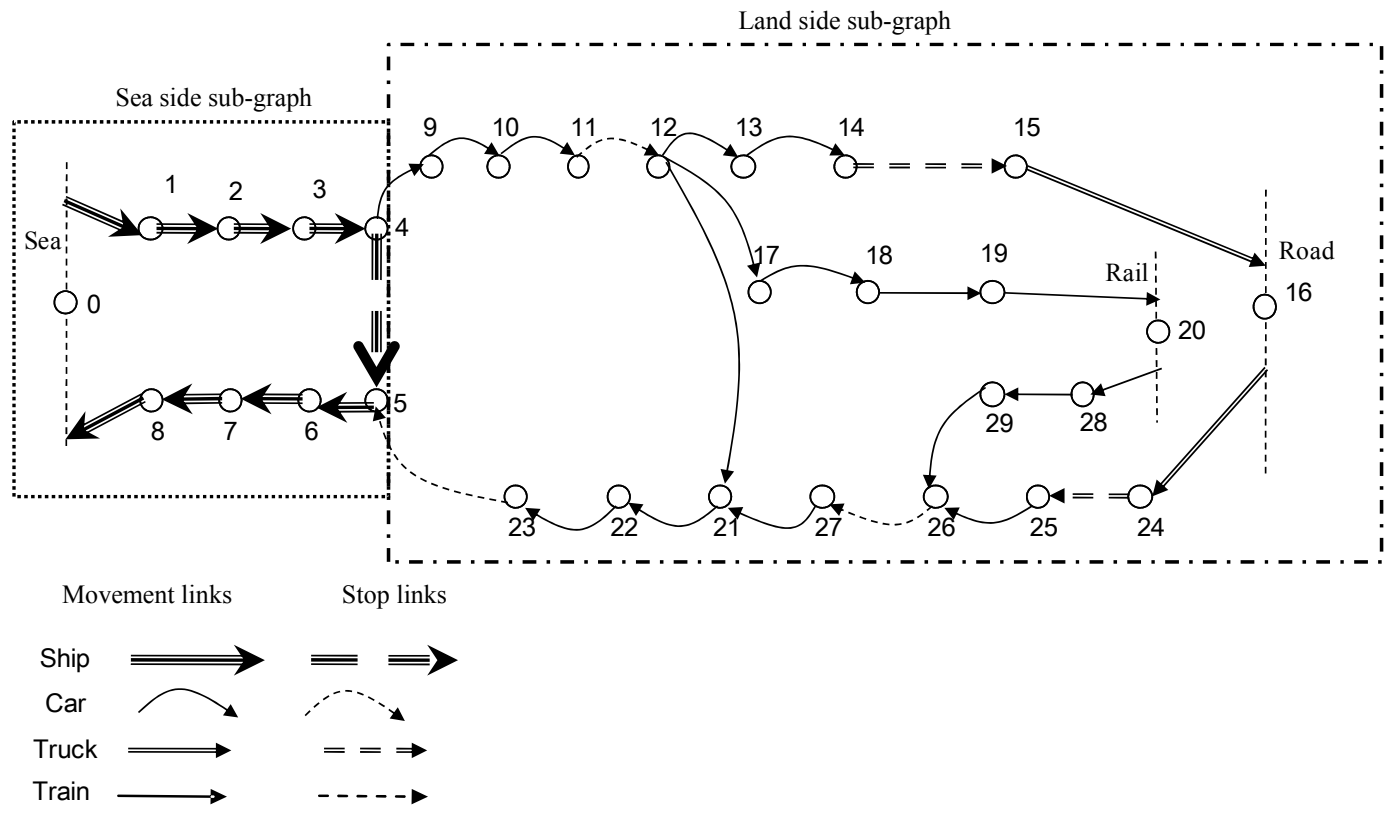

Fig. 7 Graph of ro-ro port.

and mooring (link 2-3). Generally, ro-ro ships supply line services. In other words, the arrival times at the port are scheduled and planned in advance. As a consequence, when the ship arrives near the port, it does not have to wait at anchorage before entering. Furthermore, because of the particular advancing system of ro-ro ships, the captain hardly ever demands towing. As a result, no money or time are spent for towing unless port authorities impose it for safety reasons (thus, no cost or time is associated with the link 1-2).

Once the ship is moored, the descent of the ramp (link 3-4) opens the loading/unloading operations. Once loading/unloading operations are completed (link 4-5), various activities are carried out (refuelling, fulfilment of bureaucratic obligations, etc.). Generally, these activities can be carried out during the loading/unloading operations. When such operations are concluded, the ramp is drawn in (link 5-6) and the ship is unmoored, piloted and/or towed outside the port (links 6-7, 7-0 and 8-0).

In the specific instance, once the ship is moored, the unloading operations start. Then, the motor cars, which have to be unloaded at the port, are unlashed (link 4-9). Therefore, cars must wait a certain time before disembarking: this wait (link 9-10) depends on the position occupied by the car itself on the ship. Thus, the disembarked car is positioned in the yard (link 10-11) where it is stored (link 11-12). At this point, the routes followed by the different cars inside the ro-ro port terminal differentiate according to the transport mode (road, rail, sea) used for distribution.

In case of distribution via road, the single motor car is moved from the yard to the area devoted to the formation of trailer trucks (link 12-13) and then loaded on car transporters (link 13-14) where it waits for the fulfilment of possible customs obligations (link 14-15). The trailer truck is finally sent on the road network (link 15-16).

In the case of distribution via rail, the motor car is transferred to the area devoted to the formation of the railway wagon (link 12-17). It is loaded on the wagon (link 17-18) and waits for the completion of the loading operations of the whole train, as well as for the fulfilment of possible customs obligations (link 18-19). The formed train is then sent on the railway network.

Finally, in the case of distribution via sea, the motor car is approached to the quay (link 12-21), loaded on the ship through the ramp (link 21-22) and, after being lashed (link 22-23), it waits for the end of the 
embarking operations of the other cars (link 23-25).

If the motor cars arrive the port node by road or railway, the above-mentioned operations are repeated in the opposite order.

Among the disaggregate models [10-12] useful for the evaluation of the monetary cost for an operator of ro-ro shipping, the model proposed by Gattusois is worth mentioning. According to this model, the $\operatorname{cost} C_{p}$, incurred by the MTO for the car transit at the port node, can be defined as the sum of three different components:

$$
C_{p}=C_{i / o}+C_{h}+C_{d}
$$

where, $C_{i / o}$ is the cost of entrance/exit from the port and depends on the costs incurred by the shipping company (pilotage, towing and mooring) at the same node. This cost is included in the rate the MTO pays to get the maritime service.

$C_{h}$ is the cost of car handling inside the port. It is measurable through the following expression:

$$
C_{h}=\left(\beta+c_{s t} \cdot t_{s o}+c_{h}\right) \cdot n_{a}
$$

where,

$\beta$ is the rate applied for the car handling from the ship to the yard expressed in $€ /$ motor car;

$c_{s t}$ is the storage cost in the yard (€/car per day);

$t_{s o}$ is the stop time in the yard (days);

$c_{h}$ is the handling cost from the yard to the area devoted to the formation of trailer trucks/trains (€/motor car);

$n_{a}$ is the number of motor cars loaded/unloaded from the ship.

Finally, $C_{d}$ is the cost related to the customs operations.

Regarding the temporal cost, the total time $T_{N}$, spent by a ship in a port, can be decomposed into four components corresponding to four macro-activities:

$$
T_{N}=T_{A}+T_{S}+T_{W}+T_{\text {TRUCK/TRAN }}
$$
where,

$T_{A}$ is the mooring time, that is, the time between the phase of the ship arrival in the roadstead and that of docking: it includes the pilotage, towing and mooring time (links $0-1,1-2$, and 2-3) which depends on the ship tonnage, on the infrastructural characteristics of the port and on the waiting time at the roadstead. The last-mentioned element is generally of no value because the arrivals of the ships at the port are planned in advance for line services;

$T_{S}$ is the time spent for the disembarking operations and depends on the ship typology and on the quantity of vehicles to disembark;

$T_{W}$ is the storage time of the motor cars in the yard;

$T_{\text {TRUCK/TRAIN }}$ is the time spent for the formation of the car transporter or of the car-transporting wagons and to deal with customs procedures.

\subsubsection{Aggregate Approach}

Aggregate models are often preferred in the evaluation of the transport costs of the goods across the interchange node.

The monetary costs associated to the railway intermodal node depend on the operations carried out within the terminal for the goods handling. These costs are not directly perceived by the MTO who wishes to make a consignment through the railway carrier, because it is aggregated to the fare which has to be paid in order to get the transport service.

From a temporal point of view, the cost mostly depends on the typology of railway transport used in the consignment, since this determines the minimum time of delivery at the node (Table 2, Resolution $16 / 1998$ of Italian railway managing director).

Among the aggregate models, which allow the calculation of the monetary cost at the port node with reference to the sea-side operations, the model proposed in the EU project SCENES is very interesting. Following this model, the cost at the port node $\left(C_{N}\right)$ is evaluated as the product between the quantity of handling goods $(Q)$, expressed in tons, and a unit cost

Table 2 Minimum times of delivery at the node.

\begin{tabular}{ll}
\hline Typology & Time $(\mathrm{h})$ \\
\hline Single wagon & 4 \\
Group of 3 wagons & 6 \\
Group of wagons $>3$ & $6^{*}$ \\
Complete train & 24 \\
\hline * means +1 h for each additional wagon.
\end{tabular}


parameter $\delta$, which varies according to the typology of transported product (equal to $25.5 € / \mathrm{t}$ in the case of motor cars) and includes the costs of pilotage, mooring and embarkation/disembarkation:

$$
C_{N}=\delta \cdot Q \quad(€)
$$

When motor cars are transported by road, the costs incurred at the road node are linked only to the operations of loading and unloading of the motor cars from the ship/train to the car transporters or vice versa. The following model, which is associated to these operations, is used to evaluate the monetary cost at the node $C_{n, s}$ :

$$
C_{n, s}=\lambda \cdot n_{a}
$$

where, $\lambda$ is the unit cost for the loading/unloading of the motor cars (equal to $31 € /$ car in compliance with the Bonforti Act) and $n_{a}$ is the number of loaded or unloaded cars.

\section{Application to a Real Context: The Port of Gioa Tauro}

Within this research, it has been chosen to study and evaluate, through the cost models specified in the previous paragraphs, the feasibility of new supply chains of an automotive logistics company that works in the industrial district of Gioia Tauro and deals with the transport of new cars from the Far-East (mainly Korea and Japan) to many western Mediterranean ports.

Today, the port of Gioia Tauro mainly provides a service of transhipment of the motor cars for the Mediterranean market, without absorbing the national market share. Therefore, it has been decided to study the possibility for the port of Gioia Tauro to also intercept the traffic of the motor cars destined to the Italian market, which is currently absorbed by the port of Leghorn.

The link between the port and the Italian compounds of the main car manufacturing companies could be achieved by using three different alternatives (Fig. 8):

- "all road" transportation from the port of Gioia Tauro directly to the compound;

- railway transportation between the station serving the port of Gioia Tauro and the station near the compound;

- feeder service between the ports of Gioia Tauro and of Leghorn combined to the land transport (road or railway) up to the compound.

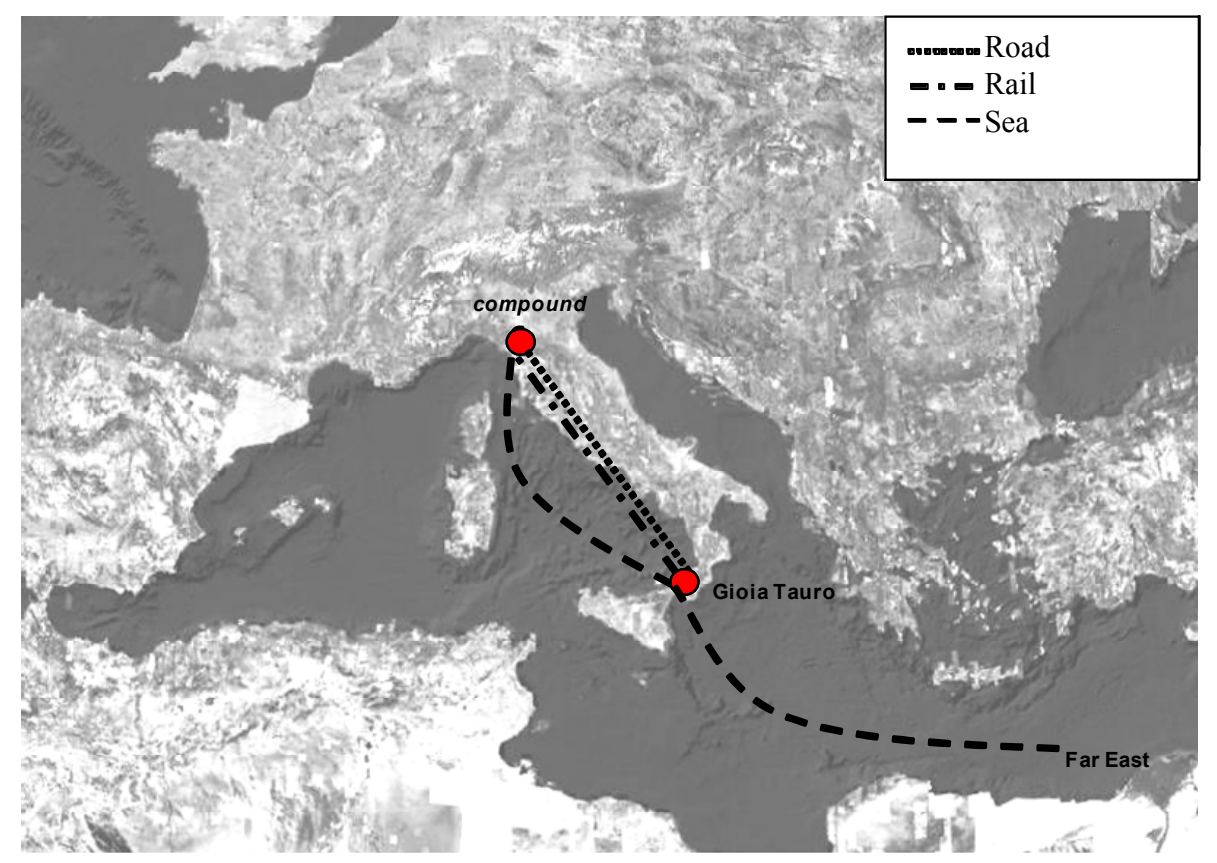

Fig. 8 Study scenarios. 
In order to compare these alternatives, it is necessary to analyze the three supply chains and to evaluate the possible convenience of the customer to choose the port of Gioia Tauro as interchange node. The methodology proposed in the previous sections has been applied with a view to determine some indicators for the evaluation of the efficiency and efficacy of a supply chain.

The logistic cost is generally the sum of different rates, among which the transport cost is that which mostly affects it. The cost can vary according to the mode of transport used. Later on in this paper, the graph used to represent the supply, suitably adapted both to the models existing in literature and to those proposed in the research, is shown. The examined supply chains are shown in Fig. 9.

As already mentioned, the disaggregate modelling of the port node is still being investigated. For this reason, although its theoretical aspects have been presented, the application has been carried out through the use of aggregate models, which have been suitably selected among those presented in literature and adapted to the specific case of the transportation of new motor cars by means of special surveys conducted with some important operators. The application of the models has allowed the calculation of the monetary and temporal costs of the alternative supply chains as well as a comparison with the present situation (Tables 3 and 4), with reference to a number of motor cars equal to 2,000 .

The comparison of the monetary costs, calculated for the phase of distribution in the different scenarios, highlights that the combined rail-sea transport, with the interchange node at the intermodal terminal of Gioia Tauro, is the cheapest solution because it allows to save money (about 45\%) compared to the present situation. In fact, the monetary costs at the port node are dramatically reduced in comparison with the present situation and the solution concerning the sea transport with feeder service in the port of Gioia Tauro.

Even when compared to the road transport, the railway alternative seems to be more convenient from a monetary point of view, since the transport unit cost is lower. As regards time, the most advantageous alternative seems to be the road link between Gioia Tauro and the compound $(-42 \%$ compared to the present situation) because of the lower costs at the interchange nodes. Of course, the study should be completed with a technical feasibility study, through the examination of available railway routes and car transporters/car-transporting wagons so that the frequency and the whole capacity of the transport service are able to meet the demand. The results of the application are shown in Figs. 10 and 11 for an in-depth analysis.
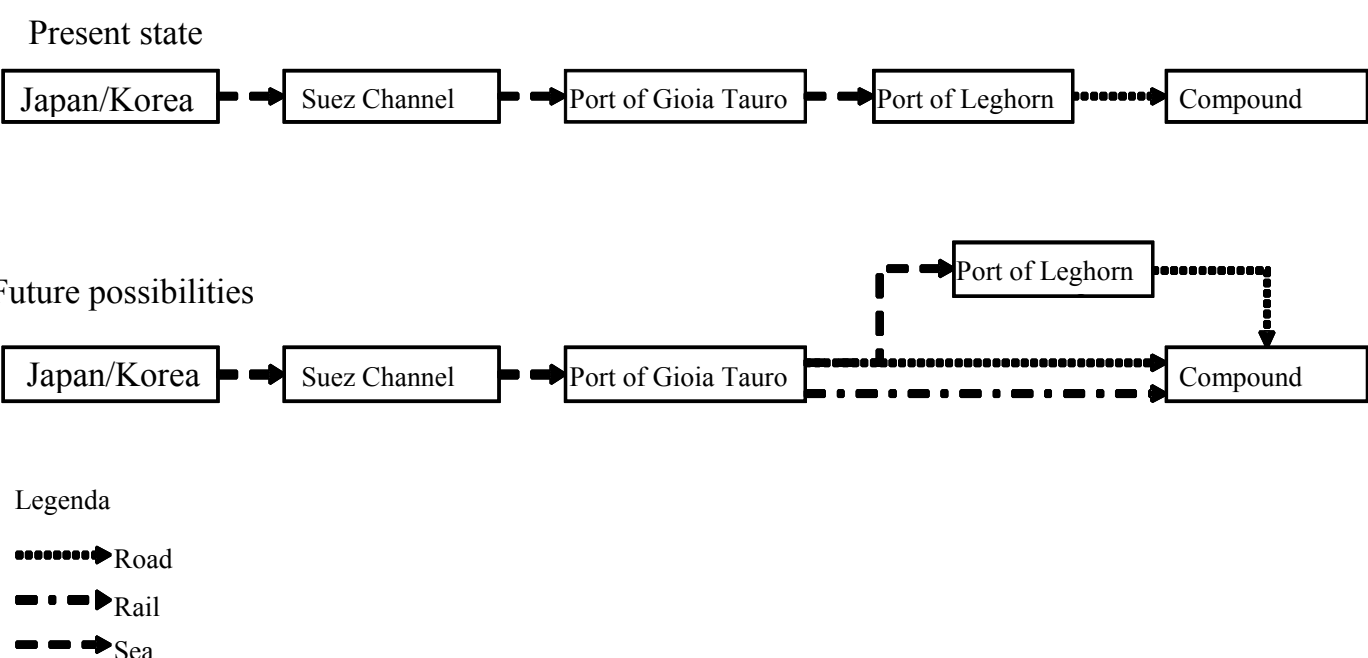

Fig. 9 Examined supply chains. 
Table 3 Monetary costs of the phase of distribution in the present and future scenarios.

\begin{tabular}{llll}
\hline Supply chain & $\begin{array}{l}\text { Unit cost } \\
(€ / \text { car })\end{array}$ & $\begin{array}{l}\text { Used cost } \\
\text { function }\end{array}$ \\
\hline Present & 461 & $(1)+(6)$ \\
\hline \multirow{3}{*}{ Future } & GT-compound road & 503 & $(6)+(1)$ \\
& GT-compound rail & 251 & $(6)+(4)$ \\
& GT-LI-compound sea & 481 & $(6)+(1)$ \\
\hline
\end{tabular}

Table 4 Temporal costs of the phase of distribution in the present and future scenarios.

\begin{tabular}{llll}
\hline Supply chain & $\begin{array}{l}\text { Unit cost } \\
(\mathrm{h} / \text { car })\end{array}$ & $\begin{array}{l}\text { Used cost } \\
\text { function }\end{array}$ \\
\hline Present & 120 & $(2)+(7)$ \\
\hline \multirow{3}{*}{ Future } & GT-compound road & 69 & $(7)+(2)$ \\
& GT-compound rail & 98 & $(7)+(5)$ \\
& GT-LI-compound sea & 179 & $(7)+(2)$ \\
\hline
\end{tabular}

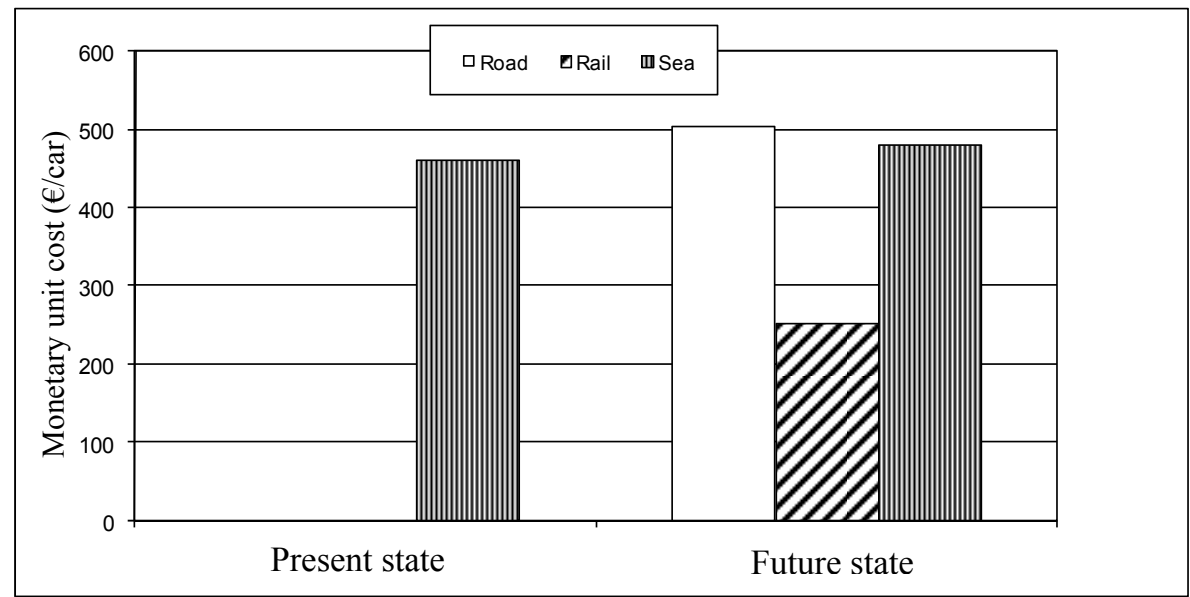

Fig. 10 Monetary unit cost.

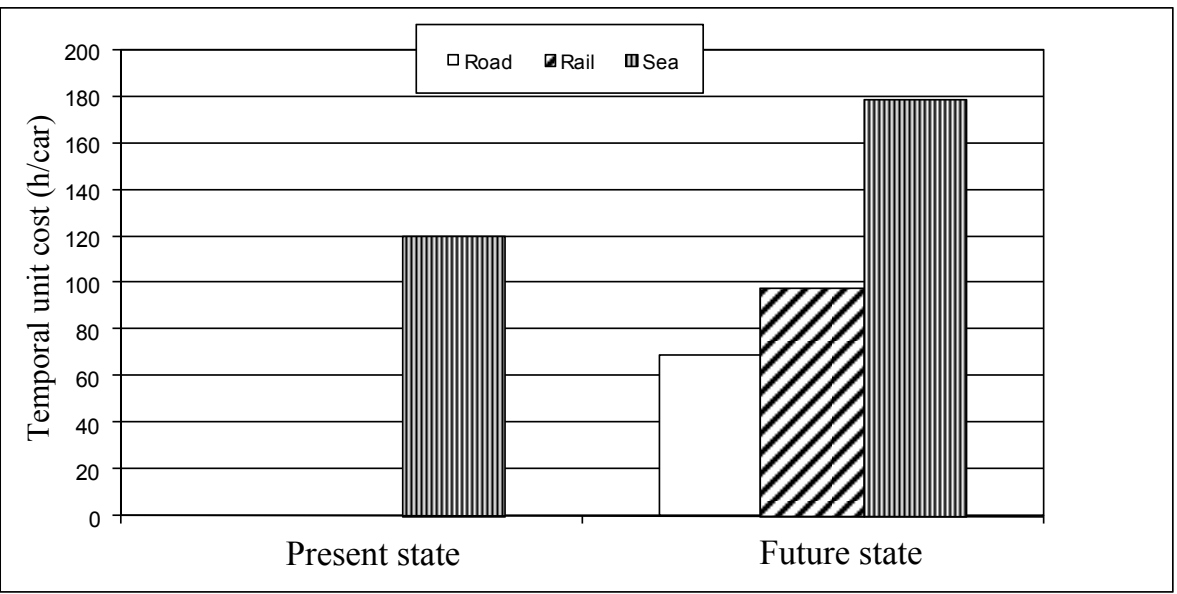

Fig. 11 Temporal unit cost.

One of the most relevant factors for the choice of the optimal solution is the service quality. It is important to point out that the automotive logistics sector is a field which is very much influenced by the quality of its end-product. The customer is extremely sensitive to the number of transhipments of the motor cars, because the higher this number, the higher the stop time of the motor cars in the storage areas and, as a result, the higher the probability to damage them.

\section{Conclusions}

This study has analyzed the automotive supply chain by distinguishing its phases and focusing on the phase of distribution/transport. Some specific models have been proposed (some taken from field literature and others appropriately quoted) for the analysis of the monetary and temporal costs incurred by a MTO when distribution takes place with one of the three most 
common transport modes (road car transporters, rail car-transporting wagons and ro-ro ship) or with their combination.

The proposed models have then been applied to the context of the port of Gioia Tauro, presently operating in the automotive field for the transhipment between the Far East and the Mediterranean countries, assuming that this port can expand its market to the Italian peninsula, in particular to the cities in the north of Italy. It has emerged that, in spite of the present trend towards road transport, the more convenient transport mode would be the sea transport up to the port of Gioa Tauro and then the use of rail transport as far as the destination compounds. Despite the encouraging results for environmental management and sustainable development, these findings clash with the present railway transport supply, which is lacking in car-transporting wagons.

Further in-depth studies, about the cost functions and the models for the evaluation of the specified times and costs, are in progress.

\section{References}

[1] M. Boario, M. de Martini, E. di Meo, G. Gross-Pietro, Manuale di Logistica (Manual of Logistic), UTET (Typographical Union-Editorof Turin), Turin, 1992. (in Italian)

[2] F. Boscacci, La nuova logistica. Una industria in formazione tra territorio, ambiente e sistema economic (The new logistic: An industry in development between territory, environment and economic system), Egea, Milan, 2003. (in Italian)

[3] M. Christopher, Logistic and Supply Chain Management, Strategies for Reducing Cost and Improving Service, Prentice Hall, New Jersey, 1998.

[4] C.F. Daganzo, Logistic System Analysis (4th ed.), Springer, Berlin, 2005.

[5] P. Dicken, Global production networks in Europe and East Asia: The automobile components industries, GPN (Global Production Networks) working paper 7, University of Manchester, 2003.

[6] F. Veloso, The automotive supply chain organization: global trends and perspectives, Working paper, Massachusetts Institute of Technology, 2000.

[7] SCENES-European Transport Scenarios, Final report, European Commission, 2000.

[8] Operative Costs of Trucks, Trimac Logistics, United States, 2001.

[9] AA.VV., Costi \& Tariffe (Costs and rates), Tuttotrasporti Review 260 (261) (2004). (in Italian)

[10] D. Gattuso, A. Polimeni, Theoretical models and operational procedures for feasibility studies of new cabotage lines, Trasporti Europei 24 (2003) 15-23.

[11] D. Gattuso, G. Cassone, A. Polimeni, Un modello per la stima delle tariffe di trasporto Ro-Ro fondato sull'analisi delle caratteristiche del cabotaggio italiano (A model to evaluate rates of ro-ro transport based on statistical analysis of italian coastal navigation), in: Proceedings of Ix Scientific Conference of SIET, Naples, 2008, pp. 273-289. (in Italian)

[12] F. Russo, Sistemi di trasporto merci (Freight Transport System), Franco Angeli Editor, Milan, 2005. 